\author{
Frédéric Pène \\ Peter Pickkers \\ Richard S. Hotchkiss
}

\section{Is this critically ill patient immunocompromised?}

Received: 13 October 2015

Accepted: 19 November 2015

Published online: 2 December 2015

(C) Springer-Verlag Berlin Heidelberg and ESICM 2015

F. Pène $(\varpi)$

Medical Intensive Care Unit, Cochin Hospital, Assistance

Publique-Hôpitaux de Paris, Paris, France

e-mail: frederic.pene@cch.aphp.fr

F. Pène

University Paris Descartes, Paris, France

P. Pickkers

Department of Intensive Care Medicine, Radboud University

Medical Center, Nijmegen, The Netherlands

\section{R. S. Hotchkiss}

Departments of Anesthesiology, Medicine, and Surgery,

Washington University School of Medicine, 660 South Euclid,

St Louis, MO 63110, USA

In a very real sense, sepsis illustrates the multiple dimensions of the immune response of critically ill patients. On the one hand, sepsis can be viewed as the simple result of the interplay between a pathogen and the immune response to that pathogen. On the other hand, it is becoming clearer that this interplay is much more complex than it appeared. It often leads to major defects in immunity during recovery, conferring increased susceptibility to secondary infections and leading to worsened outcomes [1,2].

\section{Sepsis: a syndrome with different clinical presentations}

The generic entity of sepsis, as defined by the pathological host response to infection, encompasses dichotomous clinical presentations (Fig. 1). A robust and tightly regulated early response to invading organisms is required to contain and eliminate the microbes. Both a too strong or too mild response may adversely affect outcome. A subset of septic patients infected with highly virulent pathogens may die rapidly from refractory shock, disseminated intravascular coagulation, and intractable multiple organ failure as a result of hyper-cytokinemia and uncontrolled inflammatory response. However, with improvements in acute care and resuscitation therapies, this classical exuberant presentation is relatively rare nowadays, and the physician is more often challenged by a blunted clinical response to infection, with subtle findings including lethargy or depressed mental status, glucose intolerance and hyperglycemia, hypothermia, and/or a change in the white blood cell count or cell differential.

The nature and intensity of the inflammatory response is mainly determined by the patient's background [1,2]. Sepsis is increasingly a problem for patients who have impaired immunity and who then tend to offer a blunted clinical presentation. In addition to overt immunosuppressive conditions (e.g., cancer and hematological malignancies, solid organ transplant, autoimmune and systemic diseases, HIV, use of immunosuppressive drugs), many septic patients commonly exhibit additional risk factors affecting immune status [3]. For example, chronic alcoholism, malnourishment, renal insufficiency, and liver failure all impair immunity. Another particularly important risk factor is age, since the elderly are known to have blunted immunity, a condition termed 
Fig. $1 A R D S$ adult respiratory distress syndrome, $I L-3$ interleukin-3, GM-CSF granulocyte macrophage colony stimulating factor, $I L-7$ interleukin-7, anti-PD-1/PD-L1 anti-programmed cell death-1/ programmed cell death ligand$1, I F N-\gamma$ interferon gamma

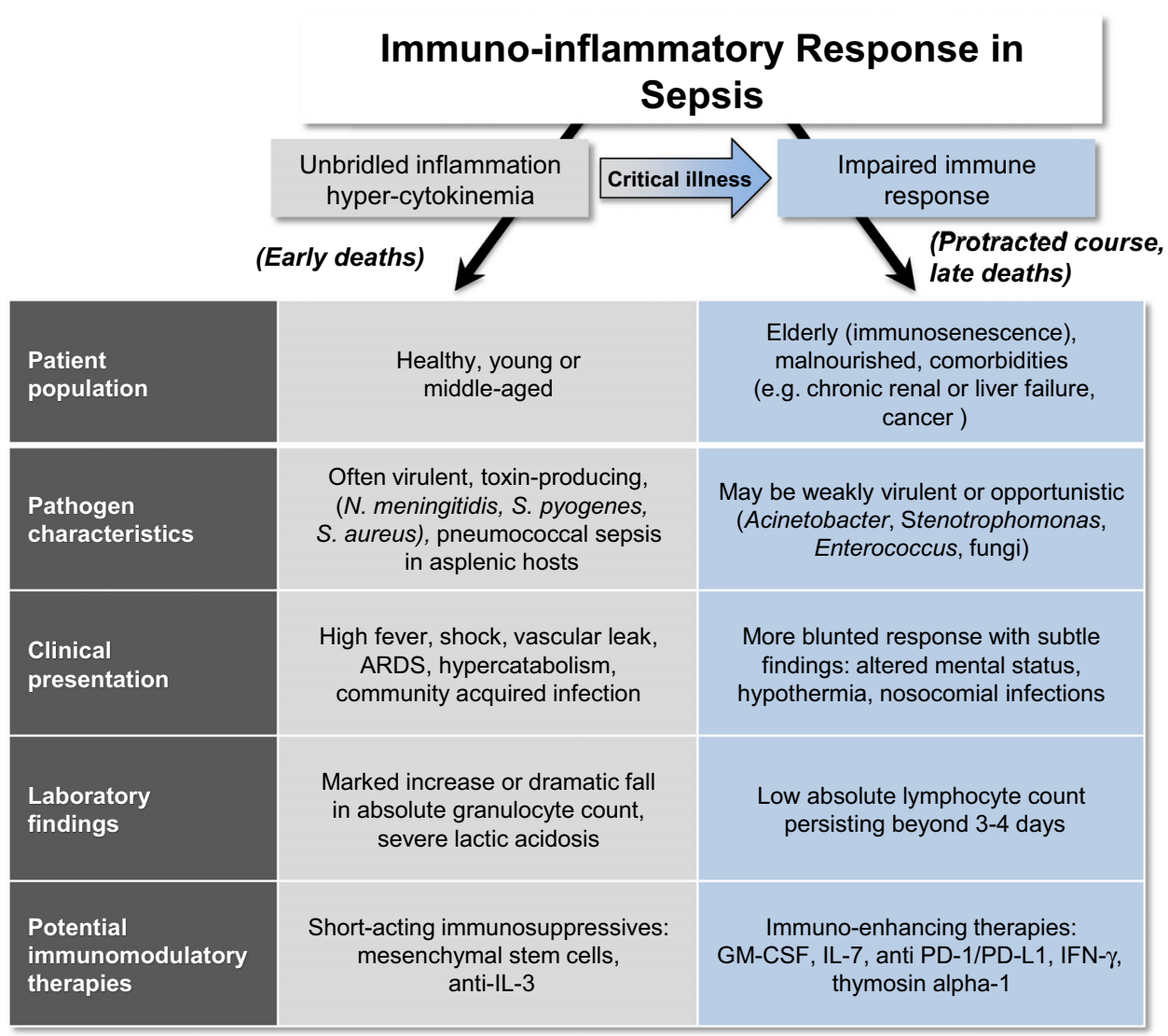

"immunosenescence". Furthermore, genetic predisposition and epigenetic changes are also hidden determinants of the host's response to infection $[4,5]$.

\section{Clinical evidence of ICU-acquired immunosuppression}

Numerous clinical and laboratory findings are consistent with new-onset or worsening of pre-existing immunosuppression in critically ill patients: loss of body temperature regulation and/or new-onset hypothermia [6]; hypoalbuminemia despite adequate nutritional support; persistent low absolute lymphocyte counts [7]. Most importantly is a failure to clear the primary infection despite source control and adequate antibiotics as well as development of ICU-acquired infections with opportunistic pathogens such as Acinetobacter, Stenotrophomonas, Enterococci, or fungal organisms [1, 2, 8]. Illustratively, over $40 \%$ of septic patients have evidence of reactivation of latent viruses, through detection of HSV in upper or lower respiratory tract with or without oropharyngeal herpetic lesions, or increased plasma HSV or cytomegalovirus DNAemia [9]. Though rarely responsible for specific organ failures, viral reactivation may add to the risk for further bacterial or fungal infections by subverting the functions of immune cells.

\section{Immunomodulatory impact of sepsis and intensive care}

On top of immunosuppressed patients being more vulnerable to sepsis, sepsis itself is profoundly immunosuppressive, and it may worsen immunity in both previously healthy and already immunocompromised patients. Sepsis induces multiple defects in innate and adaptive immunity including apoptosis-induced depletion of immune effector cells (lymphocytes and dendritic cells), monocyte deactivation, $\mathrm{T}$ cell exhaustion, increased myeloid-derived suppressor cells, and increased T regulatory cells [8]. It is noteworthy that similar immune defects have also been reported in patients suffering from severe non-septic tissue damage related to trauma, or even to major surgery, and numerous ICU therapies likely impair local or systemic immunity (e.g., mechanical ventilation, red blood cell transfusion, corticosteroids, catecholamines) [10]. The net result of these 
varying stimuli is a complex acquired immune dysfunction rendering patients more vulnerable to nosocomial infections. Striking observational studies illustrate the notion that sepsis induces an immunosuppressive state. For instance, in liver transplant patients who developed life-threatening infections, discontinuation of immunosuppressive medication did not result in transplant rejection. Only a small minority required reinstitution of immunosuppressive medications for mild evidence of organ rejection, but the dose could be reduced by $50 \%$ [11].

\section{How should development of immunosuppression impact clinical management?}

Regardless of underlying comorbidities and primary injuries responsible for ICU admission, a significant proportion of critically ill patients can reasonably be considered to be immunocompromised and at risk for ICU-acquired infections, especially if they develop overt signs of immunosuppression. Direct clinical implications include a meticulous diagnostic work-up for common sources of infection such as infected central lines, wound infections, ventilator-associated pneumonia, as well as appraising the probability of invasive fungal infections and investigating Cytomegalovirus or herpes simplex virus reactivations. Depending upon the level of suspicion and previous known colonization, it may be reasonable to start empirical antimicrobial therapy while awaiting microbial cultures. Whether a preemptive treatment of Cytomegalovirus or herpes simplex virus reactivations with antivirals may improve the outcome of critically ill patients is currently being investigated. An attractive therapeutic goal lies in the maintenance or restoration of immune response in septic patients who are recovering from the primary infectious episode. When feasible, discontinuation or reducing immunosuppressive medications is a theoretical key management principle in this setting, but may hardly be achieved in some clinical situations. This includes judicious use of corticosteroids which are still commonly used in septic shock patients, although we advocate avoiding their use whenever possible.

\section{Future implications: immuno-adjuvants to the rescue?}

The burden of nosocomial infections and the spread of highly resistant bacteria call for innovative preventive and therapeutic approaches in critically ill patients. Although there is abundant circumstantial evidence that immunosuppression is responsible for, or at least contributing to, the morbidity and mortality in sepsis, definitive evidence of its true role awaits results of clinical trials of immunoadjuvant therapy. Case series and small trials indicate that immunostimulating compounds are able to restore immune function and may exert beneficial clinical effects in sepsis patients, while no overt safety issues have been reported [12, 13]. Importantly, the identification of accurate biomarkers to detect immunosuppression in septic patients will be key to success of these trials [14, 15]. Currently, the expression of HLA-DR on monocytes as a feature of monocyte deactivation seems to be the most reliable biomarker to assess the immune status of critically ill patients. A lower expression and especially failure of restoration of HLA-DR expression appear indicative of immunoparalysis, as it is related to the susceptibility to opportunistic infections and outcome in sepsis patients [15]. Several promising immuno-adjuvant agents are slated for testing in the near future, including GM-CSF (ClinicalTrials.gov identifier: NCT02361528), IL-7, anti-PD-L1 (ClinicalTrials.gov identifier: NCT02576457), and thymosin-alpha-1 [2, 8, 12, 13, 16, 17]. Given the remarkable success of immunotherapy in cancer and the similarities in the immune defects in cancer and sepsis patients [18], it appears plausible that immunotherapy may represent a major advance in the treatment of this highly lethal disease.

\section{Compliance with ethical standards}

Conflicts of interest None.

\section{References}

1. Hotchkiss RS, Karl IE (2003) The pathophysiology and treatment of sepsis. N Engl J Med 348:138-150
2. Leentjens J, Kox M, van der Hoeven JG, Netea MG, Pickkers P (2013) Immunotherapy for the adjunctive treatment of sepsis: from immunosuppression to immunostimulation. Time for a paradigm change? Am J Respir Crit Care Med 187:1287-1293
3. Daviaud F, Grimaldi D, Dechartres A, Charpentier J, Geri G, Marin N, Chiche JD, Cariou A, Mira JP, Pene F (2015) Timing and causes of death in septic shock. Ann Intensive Care 5:58

4. Petersen L, Andersen PK, Sorensen TI (2010) Genetic influences on incidence and case-fatality of infectious disease. PLoS One 5:e10603 
5. Saeed S, Quintin J, Kerstens HH, Rao NA, Aghajanirefah A, Matarese F, Cheng SC, Ratter J, Berentsen K, van der Ent MA, Sharifi N, Janssen-Megens EM, Ter Huurne M, Mandoli A, van Schaik T, Ng A, Burden F, Downes K, Frontini M, Kumar V, GiamarellosBourboulis EJ, Ouwehand WH, van der Meer JW, Joosten LA, Wijmenga C, Martens JH, Xavier RJ, Logie C, Netea MG, Stunnenberg HG (2014)

Epigenetic programming of monocyteto-macrophage differentiation and trained innate immunity. Science 345:1251086

6. Drewry AM, Fuller BM, Skrupky LP, Hotchkiss RS (2015) The presence of hypothermia within 24 hours of sepsis diagnosis predicts persistent lymphopenia. Crit Care Med 43:1165-1169

7. Grimaldi D, Le Bourhis L, Sauneuf B, Dechartres A, Rousseau C, Ouaaz F, Milder M, Louis D, Chiche JD, Mira JP, Lantz O, Pene F (2014) Specific MAIT cell behaviour among innate-like $\mathrm{T}$ lymphocytes in critically ill patients with severe infections. Intensive Care Med 40:192-201

8. Hotchkiss RS, Monneret G, Payen D (2013) Sepsis-induced immunosuppression: from cellular dysfunctions to immunotherapy. Nat Rev Immunol 13:862-874
9. Walton AH, Muenzer JT, Rasche D, Boomer JS, Sato B, Brownstein BH, Pachot A, Brooks TL, Deych E, Shannon WD, Green JM, Storch GA, Hotchkiss RS (2014) Reactivation of multiple viruses in patients with sepsis. PLoS One 9:e98819

10. Asehnoune K, Roquilly A, Abraham E (2012) Innate immune dysfunction in trauma patients: from pathophysiology to treatment. Anesthesiology 117:411-416

11. Manez R, Kusne S, Linden P, Gonzalez-Pinto I, Bonet H, Kramer D, Fung JJ, Starzl TE (1994) Temporary withdrawal of immunosuppression for life-threatening infections after liver transplantation. Transplantation 57:149-151

12. Lukaszewicz AC, Grienay M, RescheRigon M, Pirracchio R, Faivre V, Boval B, Payen D (2009) Monocytic HLA-DR expression in intensive care patients: interest for prognosis and secondary infection prediction. Crit Care Med 37:2746-2752

13. Meisel C, Schefold JC, Pschowski R, Baumann T, Hetzger K, Gregor J, Weber-Carstens S, Hasper D, Keh D, Zuckermann H, Reinke P, Volk HD (2009) Granulocyte-macrophage colony-stimulating factor to reverse sepsis-associated immunosuppression: a double-blind, randomized, placebocontrolled multicenter trial. Am J Respir Crit Care Med 180:640-648
14. Demaret J, Villars-Mechin A, Lepape A, Plassais J, Vallin H, Malcus C, Poitevin-Later F, Monneret G, Venet F (2014) Elevated plasmatic level of soluble IL-7 receptor is associated with increased mortality in septic shock patients. Intensive Care Med 40:1089-1096

15. Landelle C, Lepape A, Voirin N, Tognet E, Venet F, Bohe J, Vanhems P, Monneret G (2010) Low monocyte human leukocyte antigen-DR is independently associated with nosocomial infections after septic shock. Intensive Care Med 36:1859-1866

16. Venet F, Foray AP, Villars-Mechin A, Malcus C, Poitevin-Later F, Lepape A, Monneret G (2012) IL-7 restores lymphocyte functions in septic patients. J Immunol 189:5073-5081

17. Wu J, Zhou L, Liu J, Ma G, Kou Q, He Z, Chen J, Ou-Yang B, Chen M, Li Y, Wu X, Gu B, Chen L, Zou Z, Qiang X, Chen Y, Lin A, Zhang G, Guan X (2013) The efficacy of thymosin alpha 1 for severe sepsis (ETASS): a multicenter, single-blind, randomized and controlled trial. Crit Care 17:R8

18. Hotchkiss RS, Moldawer LL (2014) Parallels between cancer and infectious disease. N Engl J Med 371:380-383 